\title{
Directional solidification and mechanical properties of NiAl-NiAlTa alloys
}

\author{
D. R. Johnson, X. F. Chen, ${ }^{*}$ B. F. Oliver \\ Material Science and Engincering Department. Lniversity of Tennesse. Knoxville, Tennessee 37996 220. USA \\ R. D. Noebe \& J. D. Whittenberger \\ NASA-Lewis Research Center. Cleveland, Ohis 44/35, USA \\ (Received 8 April 1994; accepted 4 June 1994)
}

\begin{abstract}
Directional solidification of eutectic alloys is a promising technique for producing in-situ composite materials exhibiting a balance of properties. Consequently, the microstructure. creep strength and fracture toughness of directionally solidified $\mathrm{NiAl}$ NiAlTa alloys were investigated. Directional solidification was performed by containerless processing techniques to minimize alloy contamination. The eutectic composition was found to be $\mathrm{NiAl}-15.5 \mathrm{at} \% \mathrm{Ta}$ and well-aligned microstructures were produced at this composition. A near-eutectic alloy of NiAl14.5Ta was also investigated. Directional solidification of the near-eutectic composition resulted in microstructures consisting of $\mathrm{NiAl}$ dendrites surrounded by aligned eutectic regions. The off-eutectic alloy exhibited promising compressive creep strengths compared to other NiAl-based intermetallics, while preliminary testing indicated that the eutectic alloy was competitive with $\mathrm{Ni}$-base single crystal superalloys. The room temperature toughness of these two-phase alloys was similar to that of polycrystalline $\mathrm{NiAl}$ even with the presence of the brittle Laves phase NiAITa.
\end{abstract}

Key words: in-situ composites. NiAl NiAlTa, directional solidification, creep resistance, fracture toughness.

\section{INTRODUCTION}

Alloys based on the ordered intermetallic compound $\mathrm{NiAl}$ have the potential to be used in high temperature structural applications due to their superior oxidation resistance, high melting point, and high thermal conductivity. 1,2 However, improvements in both the room temperature fracture toughness and elevated temperature strength are necessary before NiAl alloys can be used in loadbearing applications. Considerable research has been aimed at improving the room temperature ductility and fracture resistance of $\mathrm{NiAl}^{14}$ with only a few promising results. For example, a tensile ductility of five percent has been measured for both high purity ${ }^{5}$ and iron-doped single crystals of stoichiometric NiAl. ${ }^{6}$ In addition, room temperature fracture toughness values of the order of 24

*On leave from Materials Science Department. Shanghai Jiao University, Peoples Republic of China
MPa $\sqrt{m}$ have been measured for $\mathrm{NiAl}-(\mathrm{Cr}, \mathrm{Mo})$ eutectics that were directionally solidified to produce in-situ NiAl-based composites containing a refractory metal phase. ${ }^{7}$

Improving the elevated temperature strength of $\mathrm{NiAl}$-based alloys may not be considered as challenging as improving low temperature fracture properties. Nevertheless, very few attempts to strengthen $\mathrm{NiAl}$ have actually produced materials that are competitive with the nickel-based superalloys. ${ }^{2}$ Conventional strengthening techniques such as precipitation, solid solution, and dispersion strengthening have all been applied with varying success, ${ }^{2.3}$ with strengthening by precipitates of the Heusler phases $\mathrm{Ni}_{2} \mathrm{AlTi}$ and $\mathrm{Ni}_{2} \mathrm{AlHf}$ exhibiting the most promise. ${ }^{13.89}$ For example, Polvani et al. ${ }^{10}$ have demonstrated that the creep resistance of a two-phase $\mathrm{NiAl}+\mathrm{Ni}_{2} \mathrm{AlTi}$ alloy is significantly greater than that of the individual phases and was comparable to polycrystalline Ni-based superalloys. While impressive yield strength values have been 
measured for NiAl containing Heusler precipitates, ${ }^{2.9}$ the improved strengths of polycrystalline alloys, due to solid solution and precipitation strengthening, are diminished at low strain rates such as those in the creep regime. . $^{2.11}$

Another approach to strengthening $\mathrm{NiAl}$ consists of developing composite materials containing phases much stronger than the Heusler phase. For example, Sauthoff has suggested the use of $\mathrm{Cl} 4$ Laves compounds such as NiAINb and NiAlTa for strengthening NiAl. ${ }^{12,13}$ These phases are very brittle and have the hexagonal $\mathrm{MgZn_{2 }}$ type crystal structure. However, compressive yield strengths surpassing those of advanced nickel-based superalloys have been measured for NiAl-Laves alloys. ${ }^{13}$ In general, the improvements in strength of these two-phase alloys are proportional to the volume fraction of Laves phase present. ${ }^{12} 14$

In addition, eutectic microstructures are possible within the NiAl-NiAlNb and NiAl-NiAlTa systems allowing for in-situ composite studies. Whittenberger et al. have found that the creep strength of the $\mathrm{NiAl}-\mathrm{NiAlNb}$ eutectic is extremely sensitive to microstructure and processing conditions. ${ }^{14}$ By directional solidification of this eutectic, an order of magnitude increase in creep resistance was measured compared to materials processed using a casting and extrusion procedure. Unfortunately, the creep strength of the $\mathrm{NiAl-NiAINb}$ alloys is still less than that of most nickel-based superalloys. ${ }^{14}$

Phase equilibria in the NiAl-NiAlTa system are not very precisely defined. ${ }^{15.16}$ Nevertheless, based on Sauthoff's work ${ }^{12.13}$ with polycrystalline materials, directionally solidified alloys from this system may display better strengths than $\mathrm{NiAl}-\mathrm{NiAINb}$ alloys. Therefore, the purpose of this study was to characterize the effects of containerless processing on the microstructure, the elevated temperature strength, and the room temperature fracture toughness of in-situ composites based on the NiAlNiAlTa system.

\section{PROCESSING AND MATERIALS}

\subsection{Arc-melted ingots}

A series of alloys containing high purity $\mathrm{Ni}, \mathrm{Al}$, and $\mathrm{Ta}$ were arc-melted using a non-consumable tungsten electrode in order to identify promising microstructures for subsequent in-situ composite studies. Each button, weighing approximately $12 \mathrm{~g}$, was melted at least five times and flipped over between each melting to promote homogeneity. The arc-melted ingots were then metallographically examined. From this survey study, a neareutectic alloy of NiAl-14.5Ta (in atomic percent) was chosen for further investigation.

\subsection{Directional solidification}

Precursor ingots for subsequent directional solidification were produced by induction melting of elemental $\mathrm{Ni}$ and $\mathrm{Al}$, and a $\mathrm{Ni}-\mathrm{Ta}$ master alloy.

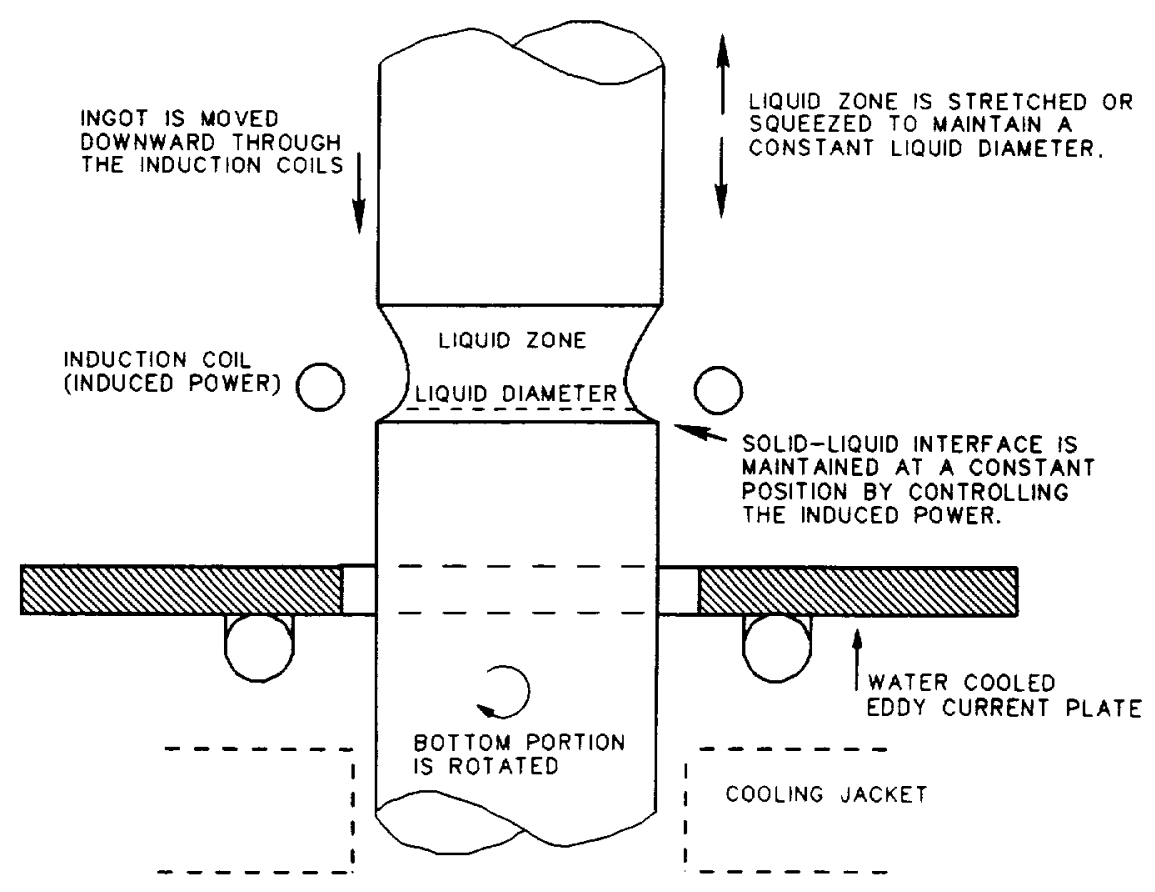

Fig. 1. Schematic of molten zone during directional solidification. 
The 1-kg charges were chill cast into a copper mold. After removal of the hot-top, the precursor ingots were nominally $25 \mathrm{~mm}$ in diameter and 300 $\mathrm{mm}$ in length. The ingots were then directionally solidified in the containerless mode by the electromagnetically-levitated zone process in ultra-pure helium atmospheres.

Containerless processing offers the advantage of enhanced purity by eliminating alloy contamination from crucible materials while simultaneously zonepurifying the initial ingot material. The crucible is eliminated by using induction power to heat, levitate, and constrain the liquid zone. Directional solidification is then accomplished by moving the liquid zone through the length of the ingot by physically traversing the ingot through the induction coil. A schematic of the levitated molten zone is shown in Fig. 1. Without crucible containment, precise dimensional control of the freezing ingot requires that the shape and position of the molten zone within the induction coils be controlled. The control variables are the position of the solid liquid interface and the liquid zone diameter (melt diameter). Current practice allows ingots to be processed under full computer control independent of any temperature measurement. ${ }^{17.18}$

Computer control is accomplished by using a digitizing camera to capture an image of the molten zone. The location of the solid-liquid interface is then found and held to a target position by controlling the induced power. The shape of the zone is controlled by maintaining a constant melt diameter by a stretch-squeeze action on the liquid, (Fig. 1). Both the interface position and the melt diameter are held to their target values by proportional, integral control loops. While not a control variable, the temperature near the solid-liquid interface is measured using an infrared pyrometer and recorded as a function of run time for all melts.

An as-processed NiAl-14.5Ta ingot and the corresponding melt record are shown in Fig. 2. The data in Fig. 2 represents the first attempt to process this material. Computer control was initiated at about $3000 \mathrm{~s}$. From Fig. 2, a constant melt diameter was maintained by a stretchsqueeze action on the liquid zone. Similarly, the position of the solid-liquid interface was controlled by varying the induced power. However, an oscillation in the interface position (Fig. 2(c)) created an unusually rough surface for the processed ingot, Fig. 2(d)). The oscillation of the interface position was caused by the target value for the melt diameter being too large. This created an unstable situation where the diameter of the freezing ingot was larger than that of the unprocessed section.

To allow for volume expansion upon melting, a gap is left between the upper and lower portions of the ingot during initial heating. If the spacing of the gap is too small, a portion of the molten zone may spill over the edge of the solid-liquid interface before a stable zone can be established creating too large a base. The tendency for the liquid zone to spill during the initial heating was a common problem for all the NiAl-NiAITa alloys processed. However, good dimensional control was obtained for all the other directionally solidified NiAl NiAlTa ingots by decreasing the freezing diameter manually before initiating computer control.

\section{EXPERIMENTAL PROCEDURES}

\subsection{Compression testing}

Cylindrical compression specimens were electrical discharge machined from selected ingots. The samples were $5 \mathrm{~mm}$ in diameter by $10 \mathrm{~mm}$ in length, with the compression axis parallel to the growth direction of the crystal. Mechanical properties were generated under both constant velocity conditions in a screw driven universal machine and under constant load conditions in lever-arm creep machines at temperatures between 1200 and $1400 \mathrm{~K}$. Constant velocity experiments were used to determine the behavior at fast strain rates $\left(>10^{7} \mathrm{~s}^{1}\right)$ while constant load testing was employed for slower rates. Overlapping steady state stress-strain rate data from the two techniques indicated excellent correlation between constant load and constant rate tests. All testing was performed in air as a secondary check for environmental resistance under load.

\subsection{Flexure testing}

Room temperature fracture toughness was determined by performing four-point bend tests on notched samples. The specimen size and test geometry are shown in Fig. 3. Bend specimens were electrical discharge machined from the directionally solidified ingots and notched perpendicular to the growth direction using a slow speed diamond impregnated saw. A fatigue pre-crack was not initiated at the notch tip prior to testing. Bend tests were performed on a servo-hydraulic test frame using a displacement rate of $7.6 \times 10^{4}$ $\mathrm{mm} / \mathrm{s}$. Fracture toughness values were calculated using the $K$-calibration for pure bending. ${ }^{19}$ 

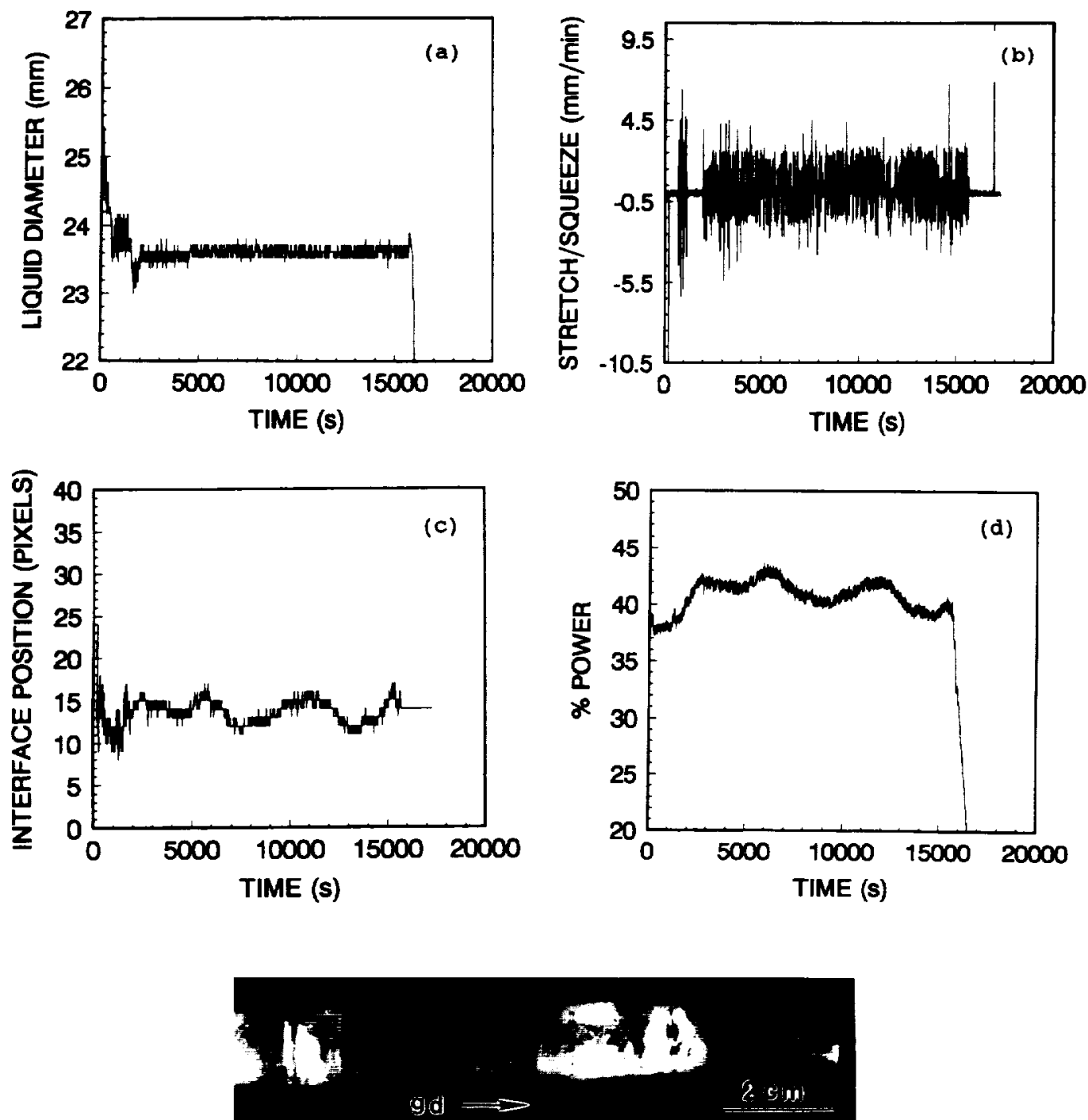

Fig. 2. Processing record for a NiAl 14.5Ta ingot: (a) diameter of the molten zone and (b) the corresponding stretch squeeze control, (c) position of the solid liquid interface and (d) the corresponding power variation, and (e) the as-processed NiAl 14.5Ta ingot (gd $=$ growth direction $)$.

To examine the effect of thermal exposure and cooling rate on fracture resistance, a number of bend specimens were heat treated prior to testing.

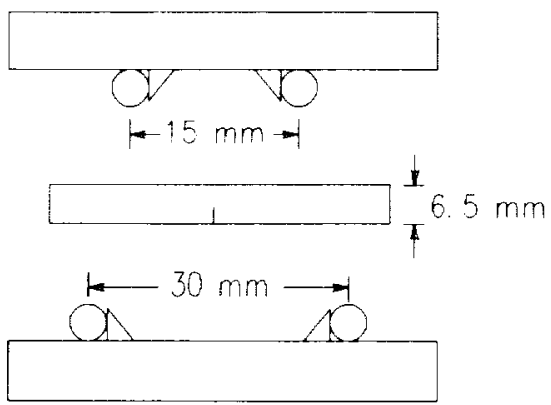

SAMPLE SIZE: $4.5 \mathrm{~mm} \times 6.5 \mathrm{~mm} \times 40 \mathrm{~mm}$ NOTCH: $2.00 \mathrm{~mm} \times 0.35 \mathrm{~mm}$

Fig. 3. Geometry of the four-point flexure testing fixture and bend sample.
The samples were heat treated in air at $1000 \mathrm{~K}$ for $7.2 \mathrm{ks}(2 \mathrm{~h})$ and either air cooled, oil quenched, or water quenched. After heat treatment, the samples were notched and the room temperature fracture toughness was determined.

\subsection{Materials characterization}

Light optical microscopy was used to characterize the general morphology of the NiAl-NiAlTa alloys. Sections taken from directionally solidified and arc-melted ingots were metallographically prepared and etched with a solution of $5 \% \mathrm{HF}-$ $5 \% \mathrm{HNO}_{3}-90 \% \mathrm{H}_{2} \mathrm{O}$ by volume.

Scanning electron microscopy (SEM) was also used to characterize the material. Backscattered electron imaging was used to help identify the phases present in the arc-melted and directionally 

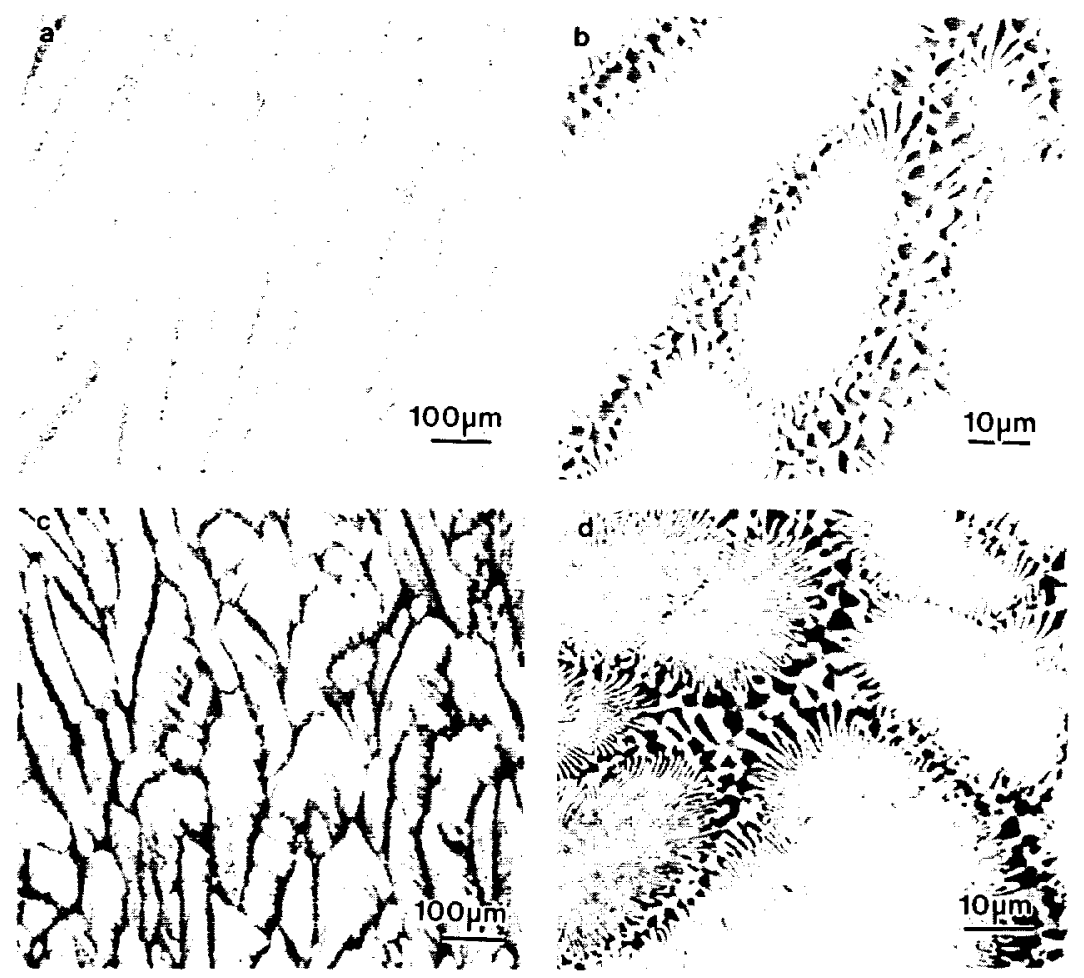

Fig. 4. SEM photomicrographs of arc-melted NiAl NiAlTa alloys having a composition of (a).(b) NiAl 14Ta, and (c).(d) NiAl 15.5Ta.

solidified ingots. Quantitative X-ray analysis of the different phases was performed on a scanning electron microscope equipped with an energy dispersive spectrometer (EDS) detector. The ' $\mathrm{ZAF}$ ' method, which attempts to correct the data for $\mathrm{Z}$ (atomic number), $\mathrm{A}$ (absorption) and F(fluorescence) effects, was used to determine the phase compositions. Finally, the fracture surfaces of the bend specimens were examined using secondary electron imaging.

Transmission electron microscopy (TEM) was used to further characterize the microstructure of the directionally solidified NiAl-NiAlTa eutectic. Thin slices were taken from broken bend specimens using a low speed diamond saw. Thinning was performed by grinding, followed by twinjet electropolishing in a solution of $5 \mathrm{vol} \%$ perchloric acid-95 vol $\%$ acetic acid at 40 volts and $300 \mathrm{~K}$.

\section{MICROSTRUCTURES}

Fully coupled microstructures consisting of $\mathrm{NiAl}$ and NiAlTa occurred in arc-melted ingots of NiAl containing 14-16 at $\%$ tantalum. These microstructures consisted entirely of the eutectic NiAl-NiAlTa and contained no single phase dendrites, Fig. 4. Since alloy compositions that contain lower percentages of tantalum are expected to have better oxidation resistance, a NiAl-14.5Ta (at $/ \%)$ alloy was initially chosen for further study. Large induction melted and drop cast ingots of this composition were directionally solidified for mechanical property evaluation.

Typical microstructures of the directionally solidified $\mathrm{NiAl}-14.5 \mathrm{Ta}$ alloy are shown in Figs 5 (a) and (b). The microstructure of this alloy consists of NiAl dendrites surrounded by aligned eutectic regions. Since the directionally solidified ingot was processed at near-equilibrium conditions, the dendritic microstructure represents an off-eutectic composition. To bettur determine the eutectic composition, another $\mathrm{NiAl}-14.5 \mathrm{Ta}$ ingot was directionally solidified with a small amount of tantalum added to the initial molten zone. The added tantalum resulted in a well-aligned microstructure in the beginning section of the processed ingot (Figs 5(c) and (d)). A bulk eutectic composition of NiAl-15.5Ta (at $\%$ ) was determined for this region by inductively coupled plasma atomic emission spectroscopy. Another NiAl-14.5Ta ingot processed in a similar manner (with additional tantalum) also resulted in a well-aligned, fully eutectic microstructure. This ingot was used for elevated temperature testing.

The NiAl-NiAlTa eutectic has a lamellar microstructure as shown by the SEM photomicrographs 

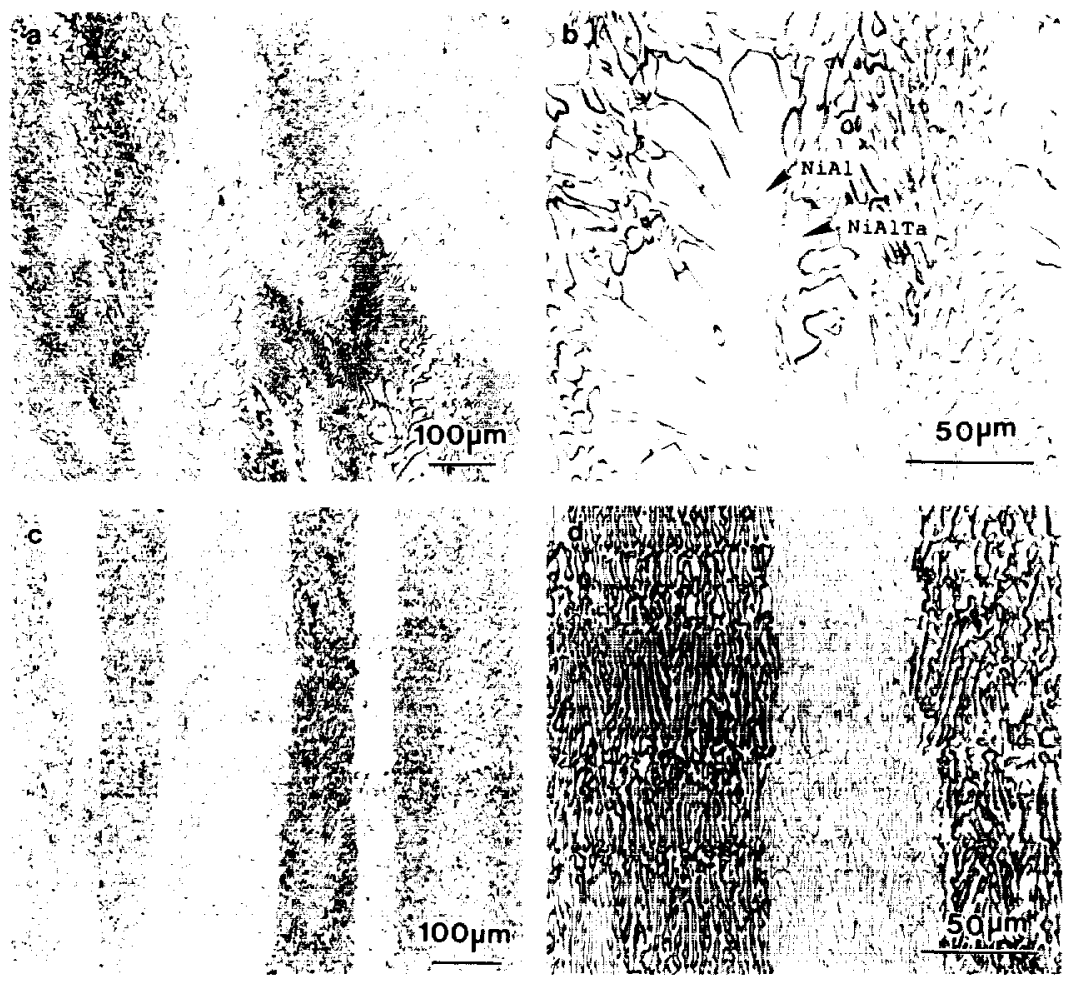

Fig. 5. Light optical photomicrographs showing (a),(b) a directionally solidified NiAl $4 \cdot 5 \mathrm{Ta}$ ingot (19mm/h) and (c),(d) a directionally solidified NiAl $15 \cdot 5 \mathrm{Ta}$ ingot $(15 \mathrm{~mm} / \mathrm{h})$.

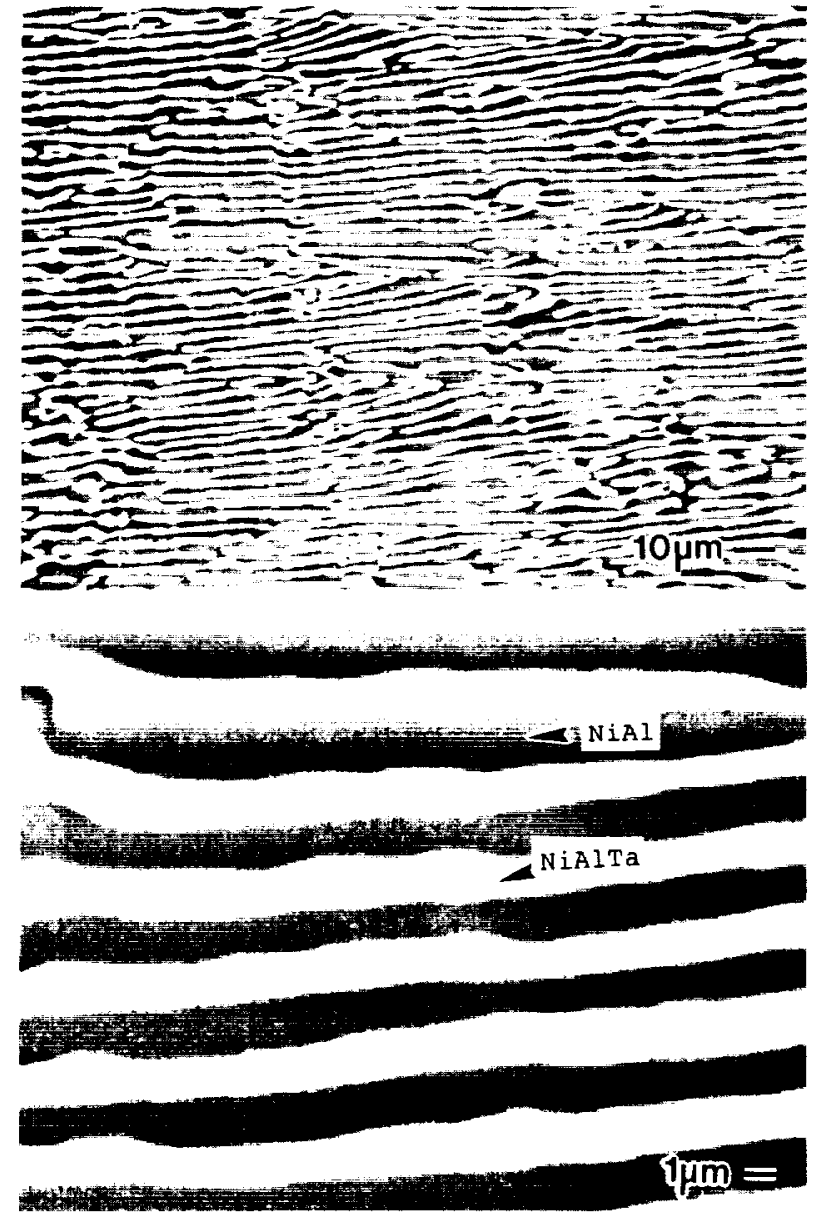

Fig. 6. SEM photomicrographs of the directionally solidified NiAl-NiAlTa eutectic (NiAl 15.5Ta). in Fig. 6. The eutectic temperature was found to be near $1820 \mathrm{~K}$ by differential thermal analysis (DTA). The volume fractions of the two phases were estimated at $53 \% \mathrm{NiAl}$ and $47 \%$ NiAlTa from SEM photomicrographs at $4000 \times$. The composition of the individual eutectic constituent for the slowly cooled directionally, solidified NiAl-15.5Ta ingot was 50.5 $\mathrm{Al}, 48.5 \mathrm{Ni}$ and 1.0Ta for the $\mathrm{NiAl}$ phase and $34.0 \mathrm{Al}$, $36.0 \mathrm{Ni}, 30.0 \mathrm{Ta}$ for the NiAlTa Laves phase as determined by quantitative $\mathrm{X}$-ray analysis. $\mathrm{A}<100>$ growth direction was found for the $\mathrm{NiAl}$ phase by selected area diffraction patterns. No definite crystallographic relationship could be determined for the NiAlTa phase.

The arc-melted versus directionally solidified microstructures were different for the NiAl-14.5Ta alloy as shown by Figs 4 and 5. The microstructure for the arc-melted ingot was essentially eutectic while the directionally solidified ingot contained dendrites of $\mathrm{NiAl}$. However, higher solidification rates and undercoolings are produced by the water cooled hearth during arc-melting compared to containerless solidification. Consequently, the difference in the arc-melted and directionally solidified microstructures suggests, that for rapid solidification rates, the coupled growth region is skewed towards lower tantalum contents at moderate undercoolings.

In an attempt to produce a more aligned microstructure in the $\mathrm{NiAl}-14.5 \mathrm{Ta}$ alloy, a cooling jacket 
Table 1. Compositions and processing conditions for NiAlNiAlTa alloys

\begin{tabular}{lccc}
$\begin{array}{l}\text { Nominal } \\
\text { compositions }\end{array}$ & $\begin{array}{c}\text { Growth } \\
\text { velocity } \\
(\mathrm{mm} / \mathrm{h})\end{array}$ & $\begin{array}{c}\text { Rotational } \\
\text { velocity } \\
(\mathrm{rpm})\end{array}$ & $\begin{array}{c}\text { Number } \\
\text { of } \\
\text { passes }\end{array}$ \\
\hline
\end{tabular}

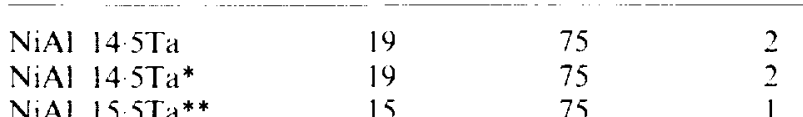

NiAl $155 \mathrm{Ta}^{* *}$

15

* Cooling jackel used for increased thermal gradient.

** NiAl 14.5Ta ingot with extra Ta added to the molten zone before directional solidification.

was mounted below the water cooled eddy current plate (see Fig. 1) during one processing run. This was an attempt to increase the thermal gradient through the solid liquid interface. A similar setup was previously used to produce successfully aligned microstructures from alloys in the $\mathrm{NiAl}-(\mathrm{Cr}, \mathrm{Mo})$ eutectic system. ${ }^{7}$ However, there was no change in microstructure for the $\mathrm{NiAl}-14.5 \mathrm{Ta}$ alloy when processed with the cooling jacket. This indicates that a much greater thermal gradient may be needed for coupled growth at this composition. The composition and processing conditions of all the directionally solidified NiAl-NiAlTa alloys evaluated in this study are listed in Table 1.

\section{ELEVATED TEMPERATURE STRENGTH}

Most of the compression testing was performed on an off-eutectic NiAl-14.5Ta directionally solidified ingot processed at $19 \mathrm{~mm} / \mathrm{h}$ with a microstructure typical of that shown in Figs 5(a) and (b). However, a limited number of tests were performed on an alloy with a fully eutectic microstructure (NiAl 15.5Ta), similar to that shown in Figs 5(c) and (d). The flow stress, $\sigma$, and strain rate, $\dot{\epsilon}$, data for these alloys were fitted to a temperature compensated-power law equation:

$$
\dot{\epsilon}=A \sigma^{n} \exp (-Q / R T)
$$

where $A$ is a constant, $\sigma$ is the steady state creep strength (MPa), $Q$ is the activation energy for deformation $(\mathrm{kJ} / \mathrm{mol}), T$ is the absolute temperature, $R$ is the gas constant, and $n$ is the stress exponent. The creep characteristics for the NiAl-NiAlTa alloys are compared to a $\mathrm{NiAl}-\mathrm{NiAlNb}$ Laves alloy and single crystal NiAl in Table 2.

The elevated temperature strength of the offeutectic NiAl-14.5Ta alloy over the temperature range of $12001400 \mathrm{~K}$ is shown in Fig. 7. Except for the fastest strain rate at $1200 \mathrm{~K}$, where powerlaw breakdown behavior has occurred, the NiAl-
Table 2. Representative creep behavior for NiAl-Laves alloys compared to binary $\mathrm{NiAl}$

\begin{tabular}{|c|c|}
\hline $\begin{array}{l}\text { Nominal composition } \\
(\mathrm{at} / 11)\end{array}$ & Representative creep behavior \\
\hline $\begin{array}{l}\mathrm{NiAl}[001] \\
(\mathrm{Ni}-50 \mathrm{Al})\end{array}$ & $\begin{aligned} & 11101300 \mathrm{~K}^{20} \\
\dot{\epsilon}= & \left(1.48 \times 10^{3}\right) \sigma^{+3} \exp (439 / R T)\end{aligned}$ \\
\hline $\begin{array}{l}\mathrm{NiAl} \mathrm{NiAlNb} \\
(\mathrm{NiAl} 16 \cdot 5 \mathrm{Nb})\end{array}$ & $\begin{aligned} & 200 \quad 1300 \mathrm{~K}:^{14} \\
\epsilon= & \left.(40.0) \sigma^{4+2} \exp \right) 4(5 / R t)\end{aligned}$ \\
\hline $\begin{array}{l}\text { NiAl- NiAlTa } \\
\text { (NiAl-14.5Ta) }\end{array}$ & $\begin{aligned} & 2001400 \mathrm{~K}: \\
\epsilon= & \left(4.55 \times 10^{7}\right) \sigma^{44} \exp (522 \mathrm{RT})\end{aligned}$ \\
\hline $\begin{array}{l}\text { NiAl NiAlTa } \\
(\mathrm{NiAl} 15 \cdot 5 \mathrm{Ta})\end{array}$ & $\begin{aligned} & 1300 \mathrm{~K}: \\
\epsilon & =\left(3.06 \times 10^{21}\right) \sigma^{601}\end{aligned}$ \\
\hline
\end{tabular}

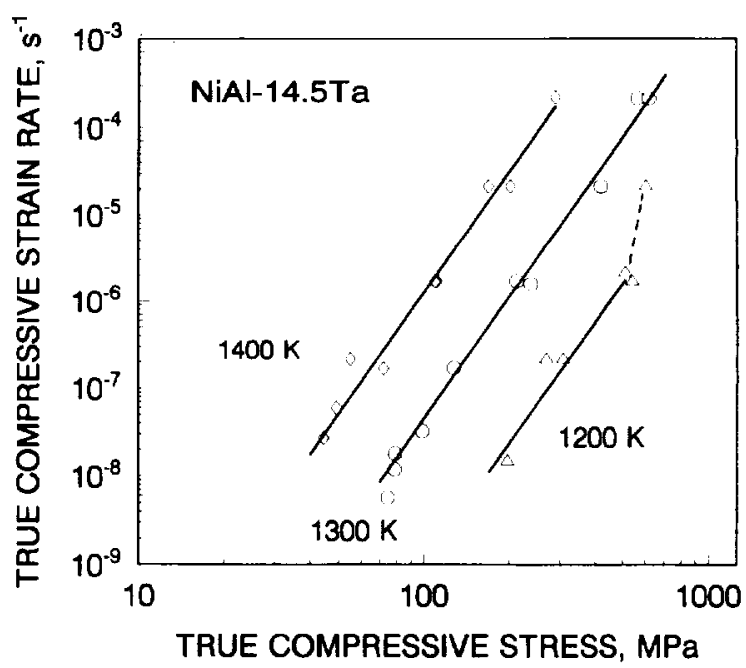

Fig. 7. $1300 \mathrm{~K}$ compressive flow stress-strain rate behavior for the directionally solidified $\mathrm{NiAl}-14.5 \mathrm{Ta}$ alloy as a function of temperature.

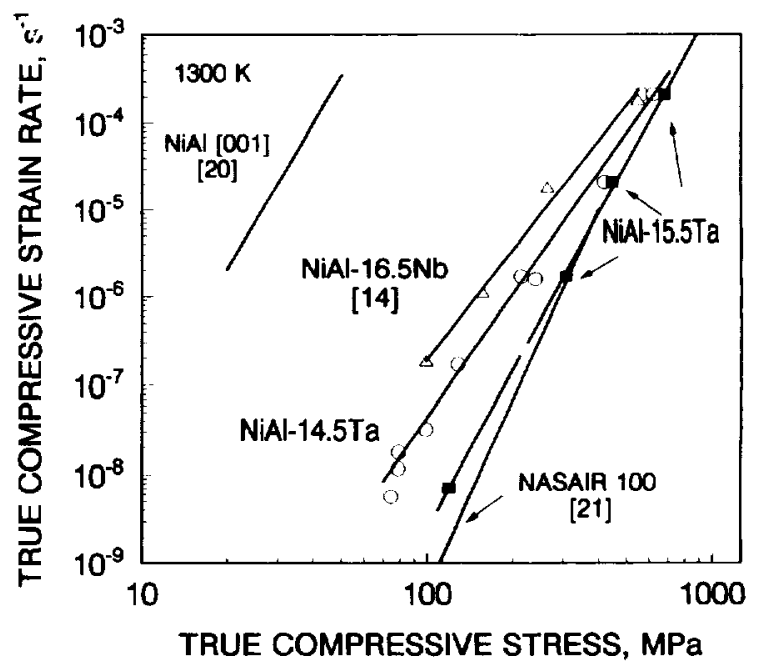

Fig. 8. $1300 \mathrm{~K}$ compressive flow stress - strain rate behavior for directionally solidified NiAI-Laves alloys compared to $\mathrm{NiAl}$ and a single crystal superalloy.

14.5Ta alloy exhibits a very consistent power law behavior over the strain rates and temperatures investigated.

In Fig. 8, the $1300 \mathrm{~K}$ compressive creep behavior of the NiAl-Laves alloys are compared to single 
crystal binary $\mathrm{NiAl}^{20}$ and a nickel-based single crystal superalloy. ${ }^{21}$ The NiAl-Laves alloys have significantly higher strengths compared to binary $\mathrm{NiAl}$. Moreover, the strengths of the NiAl-NiAlTa alloys are greater than that of the $\mathrm{NiAl}-\mathrm{NiAlNb}$ eutectic. However, the NiAl-14.5Ta alloy is still marginally weaker than a single crystal nickelbased superalloy.

Conversely, the $1300 \mathrm{~K}$ compressive strength of the NiAl-15.5Ta eutectic alloy is comparable to that of the nickel-based superalloy as shown in Fig. 8. While the data for the NiAl-15-5Ta alloy is limited to only $1300 \mathrm{~K}$ tests, the data does represent a modest improvement in creep resistance due to a modification of the microstructure. The improvement in strength is likely due to a refinement in microstructure for the fully eutectic alloy and the elimination of the large $\mathrm{NiAl}$ dendrites. The lamellar spacing of the eutectic microstructure was measured at $2-3 \mu \mathrm{m}$ from SEM and TEM photomicrographs. This is much finer than the phase distribution found in the NiAl-14.5Ta alloy (Fig. 5(b)).

\section{ROOM TEMPERATURE TOUGHNESS}

The NiAl-NiAlTa alloys exhibit brittle behavior at room temperature with a fracture toughness of approximately $5 \mathrm{MPa} \vee \mathrm{m}$. However, this is not considerably different from typical toughness values reported for single crystal or polycrystalline $\mathrm{NiAl}$ materials. ${ }^{2}$ A total of nine fracture toughness specimens were tested. Three fracture specimens were tested in the as-processed condition. The remaining specimens were heat treated at $1000 \mathrm{~K}$ for $7 \cdot 2$ ks $(2 \mathrm{~h})$ and then either air cooled, oil quenched, or water quenched. The results of all these tests are summarized in Table 3.

Table 3. Room temperature fracture toughness of directionally solidified NiAl-NiAITa alloys (NiAl-14.5Ta) after various heat treatments

\begin{tabular}{lc}
\hline Material condition & $\mathrm{K}_{\mathrm{Q}}(\mathrm{MPa} \sqrt{\mathrm{m}})$ \\
& $4 \cdot 1$ \\
As-processed & $5 \cdot 4$ \\
& $4 \cdot 1$ \\
Heat treated at $1000 \mathrm{~K}$ for $7 \cdot 2 \mathrm{ks}$, & $5 \cdot 0$ \\
Air cooled: & $4 \cdot 9$ \\
Oil quenched: & $5 \cdot 7$ \\
Water quenched: & $6 \cdot 3$ \\
& $5 \cdot 1$ \\
\end{tabular}

Table 4. Room temperature fracture toughness of alloys containing $\mathrm{NiAl}$ and Laves phases

\begin{tabular}{llc} 
Material & \multicolumn{1}{c}{ Morphology } & $\mathrm{K}_{\mathrm{Q}}(\mathrm{MPaV}$ m) \\
\hline $\mathrm{NiAl}$ & Polycrystalline (HIP) & $6^{23}$ \\
$\mathrm{NiAl}[001]$ & Single crystal (DS) & $11^{5}$ \\
$\mathrm{NiAlNb}$ & Single phase (HIP) & $2^{2 x}$ \\
$\mathrm{NiAl-NiAlNb}$ & Eutectic (cast) & $4^{28}$ \\
$\mathrm{NiAl-14.5Ta}$ & Near-Eutectic (DS) & $5 \cdot 1 \pm 0.8$
\end{tabular}

HIP = hot isostatically pressed powder metallurgy DS = directionally solidified

Hack et al $^{22}$ have shown improvements in the fracture toughness of $\mathrm{NiAl}$ when rapidly cooled through the temperature range of $673-300 \mathrm{~K}$. Their results suggest that $\mathrm{NiAl}$ may be susceptible to strain-aging embrittlement. However, the post-processing heat treatments used in this study provided no improvement in toughness of the NiAl-NiAlTa alloys and a fracture toughness of approximately 5 $\mathrm{MPa} \vee \mathrm{m}$ was measured from all samples.

In Table 4, the fracture toughness of the $\mathrm{NiAl}-14.5 \mathrm{Ta}$ alloy is compared to $\mathrm{NiAl}$ and the $\mathrm{NiAl}-\mathrm{NiAlNb}$ eutectic. The fracture toughness of the NiAl-NiAlTa alloy is comparable to that of polycrystalline $\mathrm{NiAl} .{ }^{23}$ Hence, the large increase in creep strength is not gained at the expense of fracture toughness. However, the fracture toughness of the NiAl-NiAlTa eutectic is less than that of single crystal $\mathrm{NiAl}$ having a [001] notch plane. Assuming that the fracture toughness of the NiAlTa phase is the same as that of NiAINb, i.e. $2 \mathrm{MPa} \vee \mathrm{m}$, then the fracture toughness of the NiAl-NiAlTa eutectic is very close to that predicted by the rule of mixtures, $6.5 \mathrm{MPa} \vee \mathrm{m}$ predicted versus $5 \cdot 1 \pm 0 \cdot 8 \mathrm{MPa} \vee \mathrm{m}$ measured.

Therefore, materials containing a large volume fraction of the extremely brittle Laves phase can be reliably produced, handled, and tested by processing alloys near the eutectic composition. Ironically, $\mathrm{NiAl}$ is the toughening component in these two-phase alloys. The fracture surface of a NiAl-NiAITa bend specimen is shown in Fig. 9. The eutectic microstructure is notably visible from the fracture surface as a result of partial debonding between phases during fracture. Further evidence of this fracture behavior is shown in Fig. 10. A section of the directionally solidified $\mathrm{NiAl}-14.5 \mathrm{Ta}$ ingot was polished and then broken with the polished surface in tension. The resulting fracture profile reveals a series of microcracks in the Laves phase with the $\mathrm{NiAl}$ phase bridging the crack path. In addition, cracking is also visible along the $\mathrm{NiAl} / \mathrm{NiAlTa}$ phase boundaries. 

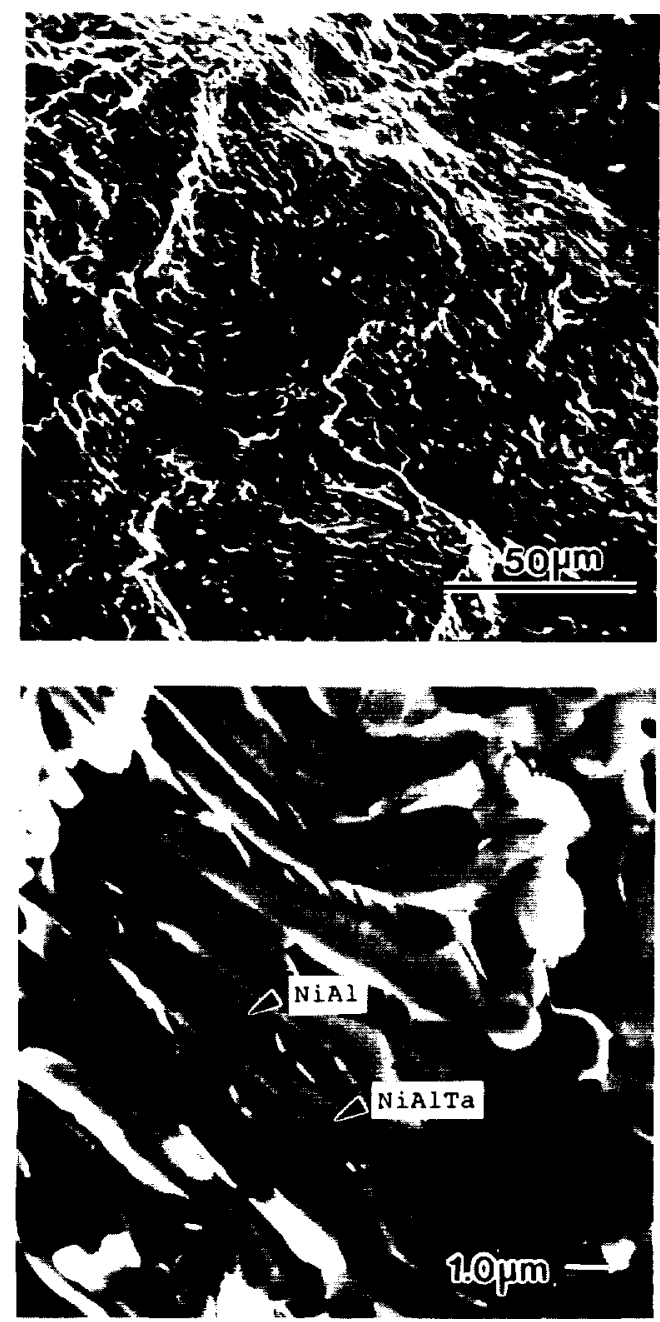

Fig. 9. SEM photomicrographs of fracture surfaces from a NiAl 14.5Ta bend specimen.

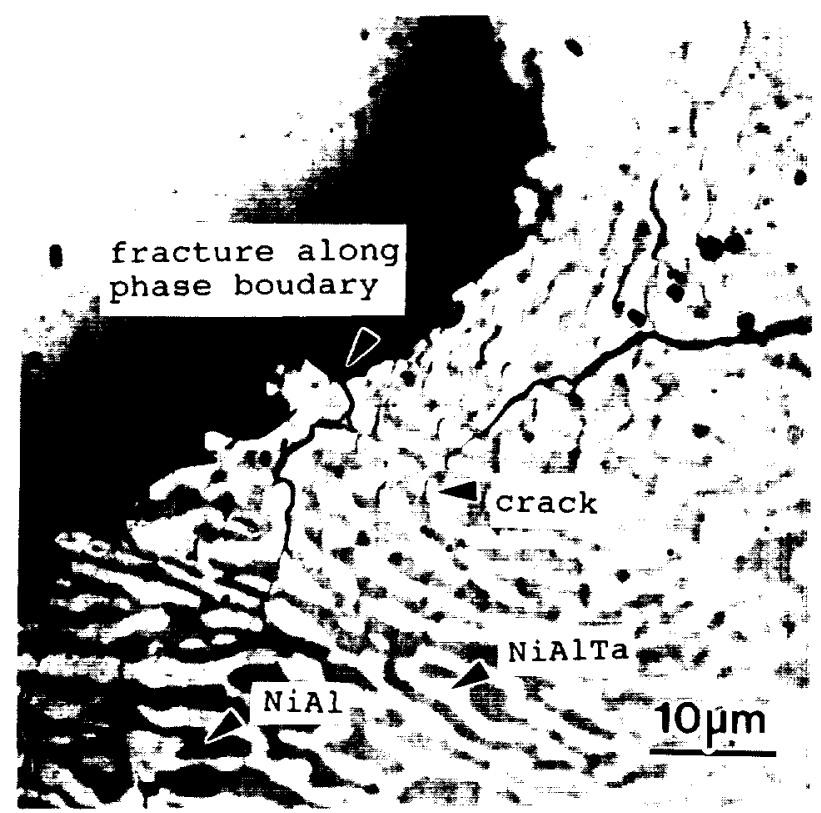

Fig. 10. Light optical photomicrograph of the fracture region from a directionally solidified NiAl $14 \cdot 5 \mathrm{~T}$ a alloy.
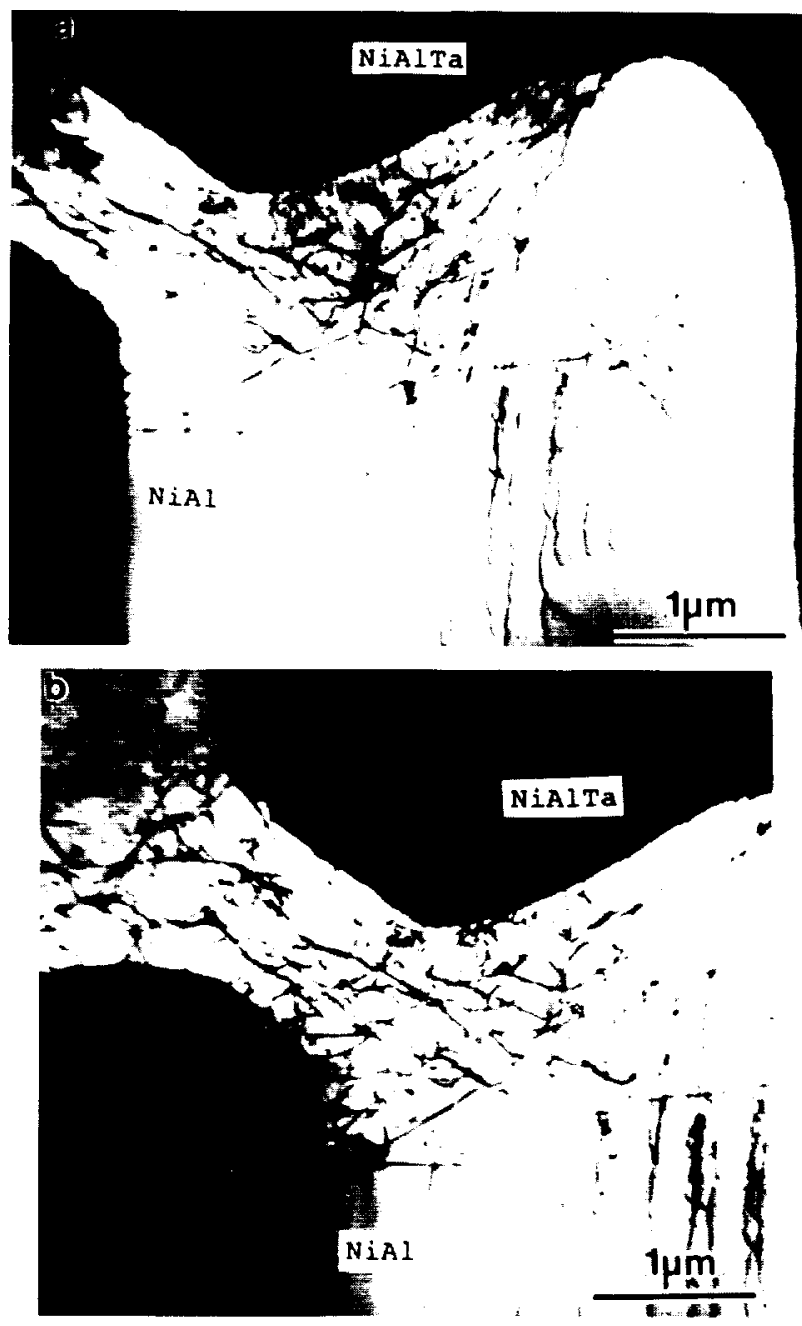

Fig. 11. TEM photomicrographs of samples taken near the fracture surface of a NiAl 14.5Ta bend specimen

Figure 11 is a TEM micrograph of the $\mathrm{NiAl}$ phase near the fracture surface of a broken bend specimen. A high dislocation density was found in the NiAl phase indicating possible plasticity of the material prior to fracture. The microstructure of $\mathrm{NiAl}$ consists of coarse dislocation tangles with the dislocation density greatest in the sections where the NiAl lamellae are the thinnest. Material taken away from the fracture surface contained a much lower dislocation density than that shown in Fig. 11. These observations suggest that the NiAl phase provides most of the fracture toughness in these brittle composite alloys as suggested by the rule of mixtures analysis. No precipitates were found in the NiAl phase.

\section{DISCUSSION}

The directionally solidified NiAl- NiAlTa alloys exhibit good creep resistance. In fact the $1300 \mathrm{~K}$ 
Performonce of Various NiAl-Based Eutectic Alloys

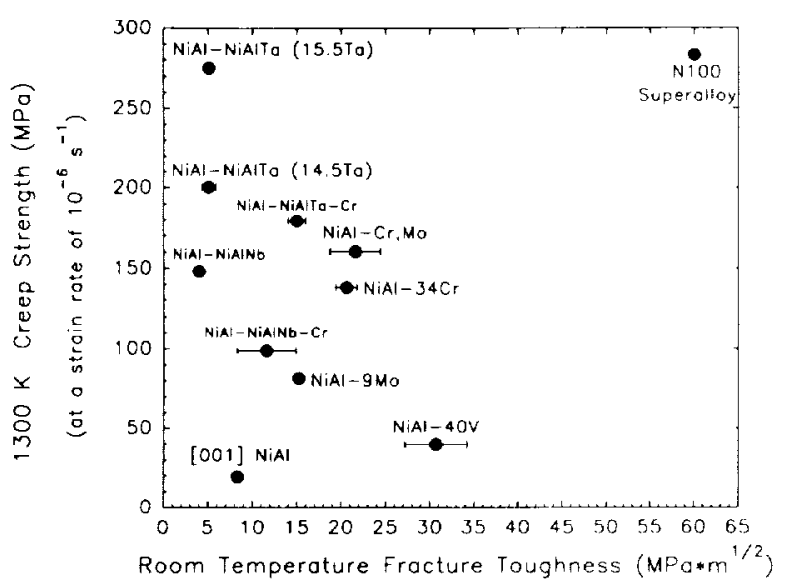

Fig. 12. Performance of NiAl-based directionally solidified eutectics compared to binary single crystal $\mathrm{NiAl}$ and a single crystal superalloy.

compressive strength of the fully eutectic $\mathrm{NiAl}-$ 15.5Ta alloy approaches that of a single crystal nickel-based superalloy (Fig. 12). The modest improvement in strength of the NiAl-NiAlTa eutectic alloy compared to the NiAl-14.5Ta alloy is probably due to a refinement of the microstructure. Sauthoff has shown that the strength of NiAlLaves alloys follows a simple rule of mixtures behavior except for very fine phase distributions. ${ }^{13,24}$ Additional strengthening is provided once the lamellar spacing becomes less than a critical value corresponding to the mean free dislocation path. ${ }^{24}$ Klöwer and Sauthoff have studied the effects of lamellar spacing on the creep behavior of $\mathrm{Ni}-\mathrm{Al}-\mathrm{Fe}$ alloys and have calculated a critical lamellar spacing of $8 \mu \mathrm{m}$ to benefit from additional contributions in strength due to phase boundary strengthening. ${ }^{25}$ The preliminary results for the creep resistance of the NiAl-NiAlTa eutectic with a lamellar spacing of 2-3 $\mu \mathrm{m}$ are consistent with their argument.

However, the directionally solidified $\mathrm{NiAl}-$ 15.5Ta alloy has a coarse eutectic spacing when compared to NiAl-refractory metal eutectics such as a $\mathrm{NiAl} \mathrm{Cr}$ and $\mathrm{NiAl}-(\mathrm{Cr}, \mathrm{Mo})$, which exhibit eutectic spacings of less than $1 \mu \mathrm{m} .^{7}$ As the eutectic spacing was relatively coarse even for the quickly cooled, arc-melted NiAl-NiAlTa alloy (Fig. 4), lamellar spacing is probably not a strong function of processing conditions. Hence further significant strengthening of the NiAl NiAlTa eutectic alloy is not expected at greater solidification rates.

One method to further improve the strength of the NiAl-NiAlTa alloys may simply be to improve the strength of the $\mathrm{NiAl}$ phase. Promising

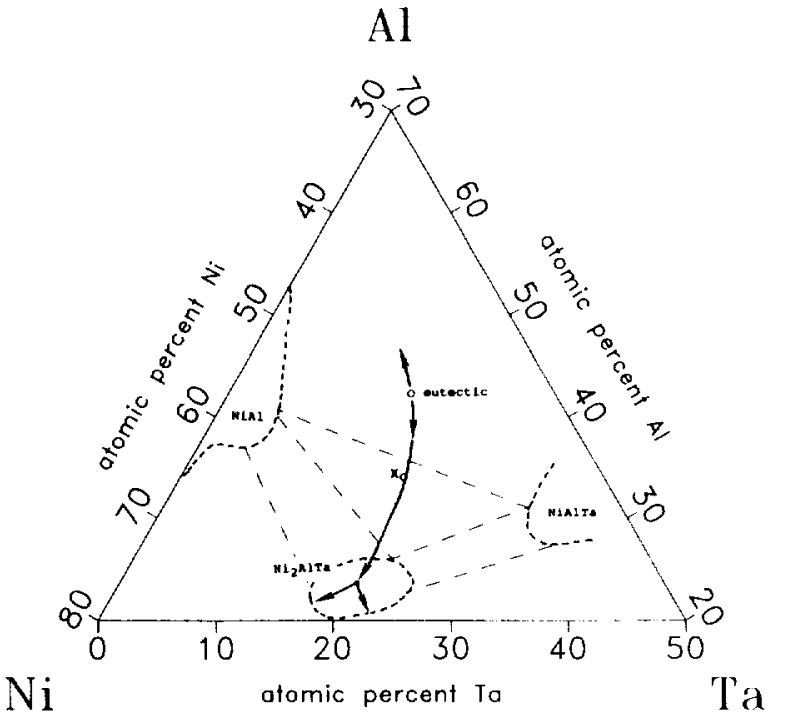

Fig. 13. A $1753 \mathrm{~K}$ isotherm from the $\mathrm{Ni}$ - Al Ta system ${ }^{16}$ combined with a schematic of the liquidus surface. ${ }^{29}$

strengths have been found for two phase material consisting of $\mathrm{NiAl}$ and the Heusler precipitate $\mathrm{Ni}_{2}$ AlTa. ${ }^{9}$ Hence, alloys heat treated in the three phase region shown in Fig. 13 may show improved strengths. For example, an arc-melted ingot with the composition near-the NiAl-NiAlTa liquidus trough (indicated by the $x$ in Fig. 13) lies well within the $\mathrm{NiAl}-\mathrm{Ni}_{2} \mathrm{AlTa}-\mathrm{NiAlTa}$ region on the $1753 \mathrm{~K}$ isotherm. The cast microstructure of this alloy (Fig. 14) consists mainly of NiAl-NiAlTa dendrites surrounded by an interdendritic Heusler phase, $\mathrm{Ni}_{2} \mathrm{AlTa}$. Post-processing heat treatments of this alloy should produce precipitates of the Heusler phase within the NiAl phase. Alloys with compositions closer to the NiAl-NiAlTa eutectic should contain smaller percentages of the interdendritic Heusler phase. Hence, it may by possible to produce aligned $\mathrm{NiAl-NiAlTa}$ microstructures with $\mathrm{NiAl}$ strengthened by the precipitates of the $\mathrm{Ni}_{2}$ AlTa phase.

While the NiAl-NiAlTa alloys show promising creep strengths, the room temperature fracture toughness of these alloys is poor. One scheme for improving the toughness is to include a metallic phase within the NiAl-NiAlTa microstructure. From Fig. 12, it is evident that the $\mathrm{NiAl}-\mathrm{Cr}$ and the $\mathrm{NiAl}-(\mathrm{Cr}, \mathrm{Mo})$ alloys have a much higher fracture toughness than the NiAl-Laves phase alloys. ${ }^{7}$ Furthermore, a ternary eutectic exits between the $\mathrm{NiAl}, \mathrm{NiAlTa}$, and $\mathrm{Cr}$ phases, ${ }^{26}$ as shown in Fig. 15. Fracture toughness and elevated temperature strength data for this ternary eutectic fall somewhere in between those of the separate binary eutectics. ${ }^{27}$ Since NiAl NiAlTa, and $\mathrm{Cr}$ are all 


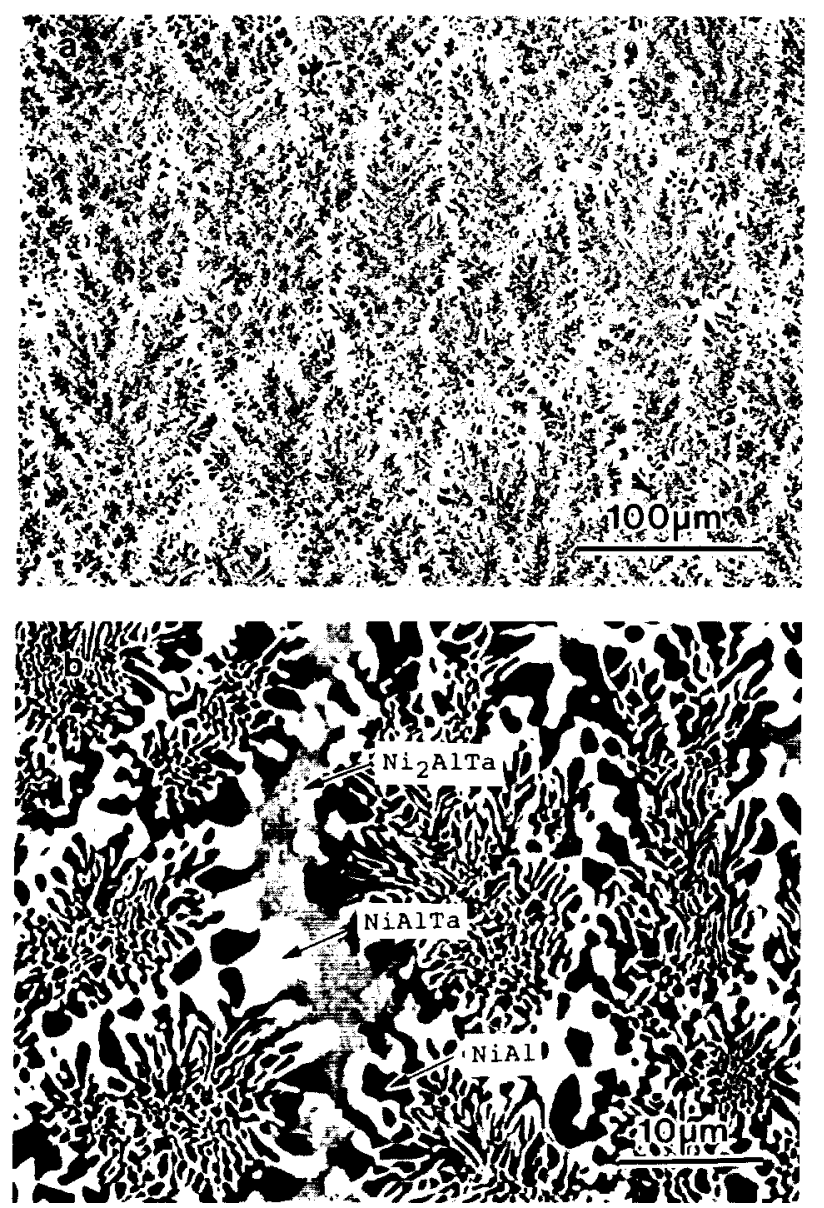

Fig. 14. SEM backscattered electron photomicrographs of an arc-melted $\mathrm{Ni} 34 \mathrm{Al} 19 \mathrm{Ta}$ alloy in the as-cast condition. thermodynamically compatible, composite materials formed by combining the NiAl-NiAlTa and the NiAl-Cr eutectics may be possible.

\section{CONCLUSIONS}

Promising creep strengths approaching that of a single crystal nickel-based superalloy were obtained in a directionally solidified NiAl-NiAlTa eutectic alloy. While the Laves phase NiAlTa is extremely brittle, materials that could be reliably handled and tested were produced by directional solidification of the NiAl NiAlTa eutectic. Through an empirical alloy design approach it may be possible to produce materials with even better creep resistance and fracture toughness by the generation of multi-phase alloys.

\section{ACKNOWLEDGEMENTS}

Appreciation is extended to Dr C. R. Brooks for his many helpful discussions and to $\mathrm{Mr} \mathrm{B}$. $\mathbf{L}$. McGill for his help with the SEM work. The authors wish to acknowledge financial and technical support from NASA Lewis Research Center through grant NAG3-876.

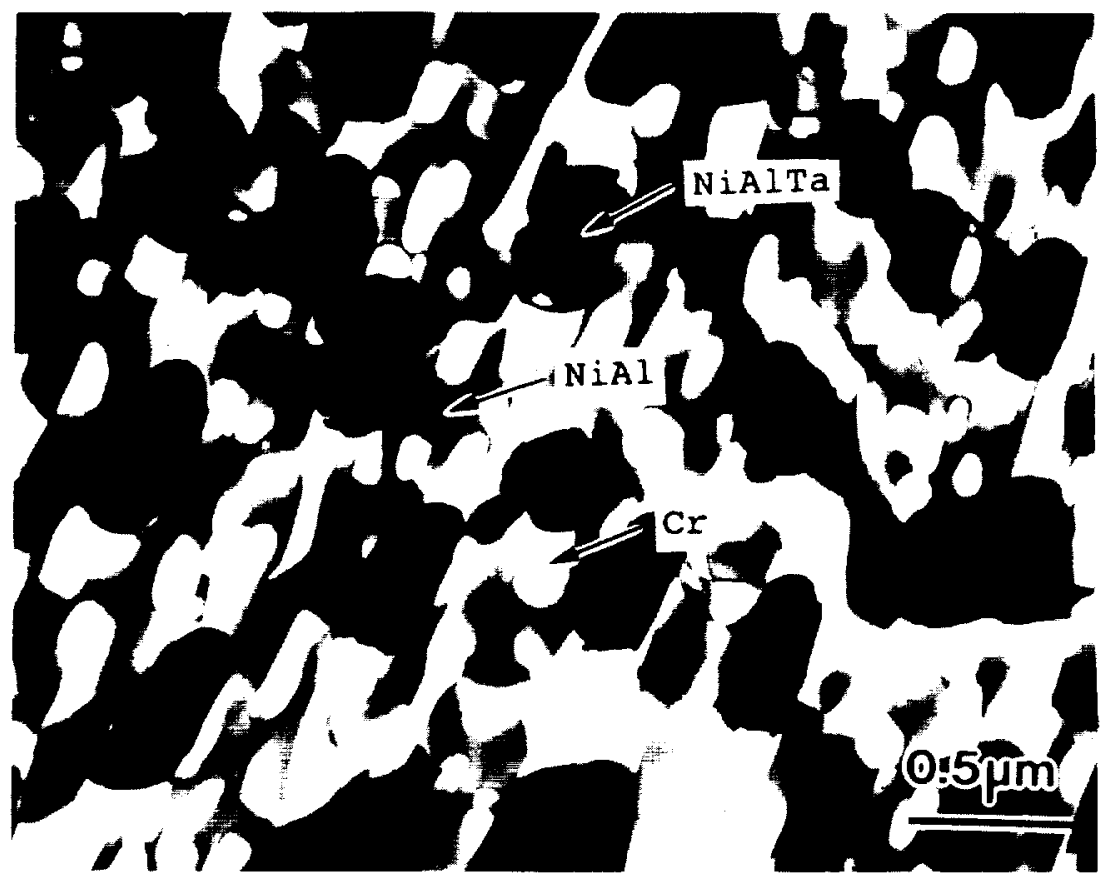

Fig. 15. TEM photomicrograph of the $\mathrm{NiAl}$ NiAlTa Cr ternary eutectic in an as-cast $\mathrm{Ni}-30 \cdot 5 \mathrm{Al}-6 \mathrm{Ta}-33 \mathrm{Cr}$ ingot. 


\section{REFERENCES}

1. Darolia, R.. JOM, 43(3) (1991) 44.9.

2. Noebe, R. D., Bowman, R. R. \& Nathal, M. V., Int. Mat. Rev, 38 (1993) 192-232.

3. Darolia, R., in Structural Imtermetallics, ed. R. Darolia et al. TMS, Warrendale, PA, 1993. pp. 495502.

4. Liu. C. T.. JOM, 45(5) (1993) 38.

5. Johnson, D. R., Joslin, S. M., Oliver, B. F., Noebe, R. D. \& Whittenberger, J. D., in lst Int. Conf. on Processing Materials For Properties, ed. H. Henein \& T. Oki, TMS, Warrendale, PA, 1993, 865-870.

6. Darolia, R., Lahrman, D. \& Field, R., Scripta Metall. Mater., 26 (1992) 100712.

7. Johnson, D. R., Chen. X. F.. Oliver, B. F.. Noebe, R. D. \& Whittenberger, J. D., accepted to Intermetallics (1994).

8. Walston, W. S., Field, R. D., Dobbs. J. R., Lahrman, D. F. \& Darolia, R., in Structural Intermetallics, ed. R. Darolia, et al., TMS. Warrendale, PA. 1993, pp. 52331.

9. Igarashi, M. \& Senba, H., in Structural Intermetallics, ed. R. Darolia, et al. TMS, Warrendale PA, 1993, pp. 53342.

10. Polvani, R. S., Wen-Shian, Tzeng \& Strutt, P. R., Met. Trams. 7A (1976) 33-40.

11. Whittenberger. J. D. Nathal, M. V., Raj. S. V. \& Pathare, V. M., Mater. Letters, 11 (1991) 26772.

12. Sauthoff, G.. Z. Metallkde., 81 (1990) 855861.

13. Sauthoff. G., in Structural Intermetallics, ed. R. Darolia et al., TMS. Warrendale PA, 1993, 37I-8.

14. Whittenberger, J. D.. Reviere, R.. Noebe. R. D. \& Oliver, B. F., Scripia Metall. Mater., 26 (1992) 987-92.

15. Nash, P. \& West. D. R. F., Met. Sci. 12 (1979) 6706.

16. Dobbs. J. R., Field. R. D. \& Konitzer. D. G., Phase
Relationships in $\mathrm{NiAl}+\mathrm{X}(\mathrm{X}=\mathrm{Zr}, \mathrm{Hf}, \mathrm{Nb}, \mathrm{Ta})$ Alloys Presented at the TMS Fall Meeting, Detroit, MI (Oct. 7-11, 1990).

17. Reviere, R. D., Oliver, B. F. \& Bruns, D. D., Mat and Manuf. Proc., 4(10) (1989) $103-31$.

18. Johnson, D. R.. Joslin, S. M., Reviere, R. D., Oliver, B F. \& Noebe, R. D., in Processing and Fabrication of Advanced Materials for High Temperature Applications-II, V. A. Ravi \& T. S. Srivatsan, TMS, Warrendale, PA, 1993, 77-90.

19. Brown. W. F. \& Srawley, J. E.. Plane Strain Crack Toughness Testing of High Strength Metallic Materials, ASTM Special Publication No. 410, ASTM, Philadelphia, PA (1966), 13-14.

20. Whittenberger, J. D. \& Noebe, R. D., unpublished data, 1991.

21. Nathal, M. V. \& Ebert. L. J., Met. Trans, A, 16A (1985) $427 \cdot 39$.

22. Hack, J. E., Brzeski, J. M. \& Darolia, R., Scripta Metall. Mater. 27 (1992) 1259-63

23. Kumar, K. S., Mannan. S. K. \& Viswanadham, R. K. Acta Metal. Mater., 40 (1992) 1201-22.

24. Klöwer, Jutta \& Sauthoff, Gerhard, Z. Metallkde., 82 (1991) 5108.

25. Klöwer, Jutta \& Sauthoff, Gerhard, Z. Metallkde., 83 (1992) 699 704

26. Johnson, D. R., Ph.D. thesis, University of Tennessee, 1994.

27. Johnson, D. R., Oliver, B. F., Noebe, R. D. \& Whittenberger, J. D., unpublished research, 1994

28. Reuss, S. \& Vehoff, H., Scripta Met, 23 (1990) 10216.

29. Johnson, D. R. \& Oliver, B. F., Mater. Letters, 1994 (in press). 